\title{
SYMPOSIUM ON INTERNATIONAL INSTITUTIONAL BYPASS
}

\section{REGIONAL INSTITUTIONS AS BYPASSES OF STATES IN THE PROVISION OF PUBLIC GOODS: THE CASE OF WEST AFRICA}

\author{
Edefe Ojomo*
}

The idea of "West Africa" encompasses a medley of countries with diverse historical, political, and cultural features. However, their governance and development profiles are distinctly similar: the United Nations recognizes eleven of the fifteen members of the Economic Community of West African States (ECOWAS) as least developed countries. In this context, regional institutions are usually established to strengthen state capacity by providing resources to address national capacity deficits. Above all, they serve as systems of support that are supplementary to state institutions with distinct governance roles. However, regional institutions can — and should—play a second role: serving as alternatives to weak or fragile state institutions that are deficient in the supply of different public goods. By performing this second role, regional arrangements become international institutional bypasses.

This essay discusses how regional institutions in West Africa operate as bypasses, because of the fragility of national institutions. Since they are not established or equipped to serve as alternatives, however, their success in this regard is limited. Therefore, institutional development must be targeted at enhancing the bypass role of these institutions so that they can better address the governance challenges of their member states. This enhanced role, however, raises important questions about legitimacy and sovereignty that have not been addressed in the framing essay.

\section{Regional Institutions as Bypasses}

Technically, a bypass creates an alternative without eliminating the original or previous institution that performed certain functions. The bypassing institution may not have been established to offer an alternative, but may be forced to play it because of its relationship with, and the deficiencies of, the bypassed institution. As a result, the bypassing institution may become an unintentional bypass, and this may create the risk that neither the bypassing nor the bypassed institution will effectively perform the function. Where this is the case, resources could be applied towards sustaining both institutions for the performance of the same function. While maintaining both could be regarded as inefficient, the social and political costs of eliminating bypassed institutions may surpass those produced by the resulting inefficiency. ${ }^{1}$ The social and political costs may be particularly high when the bypassed institution carries strong political significance, as is the case with sovereign states.

As the framing essay suggests, functional deficiencies in national institutions may require the introduction of bypasses at other levels, so that, even as states preserve their role as primary governance actors, their functions are

* Lecturer, Faculty of Law, University of Lagos; JSD Candidate, New York University School of Law. This work, was completed as part of the International Collaboration for Capitalizing on Cost-Effective and Life-Saving Commodities (i4C) that is funded through the Research Council of Norway's Global Health \& Vaccination Programme (GLOBVAC Project \#234608). ${ }^{+}$

${ }^{1}$ See the discussion of "inefficiency by design" in political institutions in Oliver Williamson, The Mechanisms of Governance (1996).

The American Society of International Law and Edefe Ojomo (C) 2017. This is an Open Access article, distributed under the terms of the Creative Commons Attribution licence (http://creativecommons.org/licenses/by/4.0/), which permits unrestricted re-use, distribution, and reproduction in any medium, provided the original work is properly cited.

\footnotetext{
${ }^{\dagger}$ Funding information has been added since original publication. See 10.1017/aju.2017.78
} 
performed by other actors. Regional organizations would be regarded as bypasses of state institutions where they (1) engage directly with targets such as individuals and private organizations, (2) perform functions that are generally regarded as those of the state, rather than simply supplementing state activities, and (3) conduct their activities through a governance structure that is separate from those of the state institutions. In these instances, regional institutions cannot be said to supplement the state, but rather to provide alternative governance targets to address specific needs, such as healthcare.

It is possible to conceive of at least two different ways in which regional institutions will operate as bypasses. On the one hand, regional organizations can bypass states through indirect means, by engaging intermediaries to make rules, conduct operations, and regulate the behavior of their targets. This way, they avoid the political implications of taking on strong governance roles generally reserved for states. ${ }^{2}$ On the other hand, direct bypasses can exist where regional organizations play roles that are not effectively performed by states. ${ }^{3}$ In states with fragile governance institutions, a direct bypass is not only a frequent occurrence, but can be considered a necessity. ${ }^{4}$

Even in instances of state fragility, concerns about sovereignty make it difficult to employ direct bypasses. ${ }^{5}$ This is even more problematic where the states affected by the bypass exercise significant control over the potential bypass institution. ${ }^{6}$ The capacity deficits of states—and of regional institutions-reveal the need for support or assistance to perform governance functions, but increased capacity alone may not fill the functional void. In order to guarantee their relevance, bypassing institutions will have to overcome the comprehensive governance challenges of their predecessors, and these usually go beyond capacity and involve legitimacy issues.

Regional institutions may be well placed to address the governance challenges-especially those related to legitimacy — of their member states because they, amongst other things, open up communities that are constrained by state borders and deemphasize the power of the state. As a result, they can build the capacity of their member states while also enhancing their legitimacy. While well positioned to do this, they may not always be well equipped to do so. In many cases, eliminating the bypassed or the bypassing institution does not seem a feasible option. The conundrum is illustrated by the case discussed below, which supports the need for innovative institutional fixes.

\footnotetext{
2 Tine Hanrieder explains how the World Health Organization uses intermediaries to promote operations in disease surveillance beyond the scope of its mandate in order to bypass the control of states. See Tine Hanrieder, Who Orchestrates: Coping with Competitors in Global Health, in International Organizations as Orchestrators (Kenneth W. Abbott et al. eds., 2015).

${ }^{3}$ Definitions of state fragility usually cover unwillingness and inability of states to perform basic functions such as supplying basic needs of their citizens. See Fragile States, OECD Glossary OF STATISTICAL Terms (2007). In instances of severe fragility, an international organization may intervene to perform governance functions, as has been the case with international transitional administrations. See, e.g., RICHARD Caplan, A New Trusteeship? International Administration of War-Torn Territories (2002) (discussing the role of transitional administrations set up by international organizations in postconflict societies with a wide range of governance roles, including law enforcement, public administration, and infrastructure development).

${ }^{4}$ Thomas Risse explains the need for "functional equivalents" of governance actors in "areas with limited statehood." See GoverNANCE Without a State? Policies and Politics in Areas of Limited Statehood (Thomas Risse ed., 2013).

${ }^{5}$ State sovereignty allows states to claim authority over their territory, even where there is no real capacity to exercise such authority. This has led to the distinction between positive and negative sovereignty. See Robert Jackson, Quasi-States: Sovereignty, InTERnational Relations and the Third World (1993).

${ }^{6}$ I refer to this as a potential bypass because states do not, when creating these institutions, recognize them as - or intend for them to be-bypasses. In the case of the West African Court, for example, the absence of limiting jurisdictional rules makes the ECOWAS Court of Justice a bypass institution, but even this does not appear to have been done on purpose and enforcement of judgments remains a challenge for the Court. See Edefe Ojomo, Competing Competencies in Adjudication: Reviewing the Relationship between the ECOWAS Court and National Courts, 7 Afr. J. LEg. STUd. 87 (2014); Karen Alter et al., A New International Human Rights Court for West Africa: The ECOWAS Community Court of Justice, 107 AJIL 737 (2013).
} 


\section{Public Health in West Africa: WAHO as an Unintentional Bypass}

Historically, regional health governance in West Africa was set in a postcolonial frame, with Francophone countries converging in 1960 to form the Organisation de Coordination et de Coopération pour la lutte contre les Grandes Endémies ${ }^{7}$ and Anglophone countries forming the West African Health Community in 1974. In 1975, ECOWAS was established to integrate West African states for the promotion of economic growth and development in the region. In addition to its central economic objective, the 1975 ECOWAS Treaty recognized the importance of social and cultural cooperation amongst member states. ${ }^{8}$ In 1987, as part of ongoing efforts to rationalize regional institutions in West Africa, the Anglophone and Francophone health agencies were merged to form the West African Health Organization (WAHO), a specialized institution of ECOWAS. WAHO was established for "the attainment of the highest possible standard and protection of health of the peoples in the sub-region through the harmonisation of the policies of Member States, pooling of resources, co-operation with one another and with others for a collective and strategic combat against the health problems of the sub-region." Its role is generally regarded as supplemental and coordinative, assisting states and encouraging cooperation in health matters.

In ECOWAS member states, national health institutions such as ministries, research units, and hospitals continue to operate under significant constraints, such as funding limitations, personnel shortages, and institutional deficits. As such, WAHO has had to play an even greater role than it has been prepared for, given its general mandate. Since member states' capacity to provide basic health facilities to their citizens is deficient, WAHO has had to act as an alternative supplier of public health services and infrastructure. This was revealed distinctly in its response to the 2014 Ebola outbreak.

When the Ebola outbreak began in Guinea, Liberia, and Sierra Leone, the inability of national healthcare systems to handle the outbreak quickly became evident. WAHO had to intervene in a way that it had not done before and that was not anticipated within its mandate and operations. While waiting for approval from the ECOWAS Authority of Heads of State and Government, the WAHO Secretariat had to mobilize financial and human resources to execute a regional response to the outbreak. As part of its response, WAHO initially deployed a technical team and subsequently mobilized healthcare personnel from across the subregion. WAHO mobilized more than one hundred healthcare professionals from across the subregion and worked with the African Union to mobilize more than seven hundred additional health workers from across the continent. This was done in the midst of intense international engagement on the ground, involving intergovernmental organizations like the United Nations, international nongovernmental organizations like Médicins sans Frontières, and bilateral partners. But, owing to its own institutional challenges, WAHO was unable to provide the leadership to coordinate these efforts - a role that it was best positioned to play given the challenges of the member states.

Much like the World Health Organization, WAHO had seen itself as a technical body responsible for formulating regional health policy and for the coordination of health systems and facilities in the region. However, the urgency of the Ebola epidemic forced WAHO to perform operational functions that transformed it into an alternative governance structure within member states.

The Ebola outbreak was not the only instance in which this happened. Owing to the challenges faced by national institutions in West Africa, WAHO has instinctively had to play this role in other occasions, often in more subtle

\footnotetext{
7 The organization's name can be translated as the "Organization for Coordination and Cooperation in the Fight against Epidemics."

8 Treaty of the Economic Community of West African States (ECOWAS) art. 2, May 28, 1975, 35 I.L.M. 660. The treaty was revised in 1993 to include a broader objectives section (Article 3) that recognized health as one of the areas of cooperation amongst member states, while Article 61 identifies health as one of the social affairs on which states are to cooperate.

${ }^{9}$ Protocol A/P.2/7/87 on the Establishment of a West African Health Organization art. III, July 9, 1987, 114.6 KiB 894.
} 
ways than an emergency like the Ebola epidemic. Before revising its role in response to the Ebola outbreak, WAHO's programs generally involved some operational functions. An ongoing WAHO project, undertaken in partnership with the German Bank Development Bank, Kreditanstalt für Wiederaufbau, focuses on reproductive health planning and community health screening in ECOWAS member states, which involves, amongst other things, direct delivery of healthcare services to cross-border communities. WAHO is also involved in training and capacity building for traditional health workers and pharmaceutical companies. While some of these projects are done in collaboration with national health ministries and are not regarded as falling outside the regional mandate of WAHO, they generally involve direct intervention and interface with governance targets.

These examples suggest that WAHO was not designed to operate as a bypass and does not do so intentionally. Due to the particular circumstances in which it is immersed, it is forced to act as a bypass, but it is not clear that WAHO or its member states would describe its role as such.

\section{WAHO's Role: Cooperation, Competition, or Control?}

The framing essay defines international institutional bypasses according to a set of features that WAHO possesses. First, WAHO does not replace national health governance institutions. Rather, it maintains national systems in place and seeks to improve their performance while at the same time providing an alternative means to performing governance functions. Additionally, by operating at both the national and regional levels, WAHO operates in the same legal regime as national health institutions. Most of the time, it works with national institutions while also providing an alternative means for people and institutions in member states to receive services that national institutions may not be able to provide. Finally, WAHO has a distinctive governance structure and operates within legitimate legal systems that define and constitute the national, regional, and global health governance regime.

Despite these features, WAHO's status as a bypass is not exempt from challenges and tensions. The Ebola response showed how WAHO struggled to play a role that was outside of its supplemental role defined by its technical mandate. WAHO was forced to provide an alternative to fragile state institutions, and this revealedparticularly to officials at WAHO_the need for WAHO to act as a bypass.

WAHO's supplemental role is relevant to discussions about its bypass role. ${ }^{10}$ Although the Organization recognizes that it should provide assistance and support to member states, it does this within the confines of state control. This means that WAHO has generally been careful not to infringe on member states' sovereignty. An important question is whether enhancing WAHO's role to include the bypassing function would generate tensions with the idea that it should operate within the confines of state control.

Although WAHO has a distinct governance structure separate from that of member states, the latter form part of this governance structure, raising interesting questions about principal-agent relations and the legitimacy of alternative governance structures. There are elements of cooperation, control, conflict, and competition that drive the performance and interactions of these institutions. In this particular instance, the bypass cooperates with the government that controls the bypassed institution (e.g., a country's health care system) in order to strengthen the latter. The bypassed institution may not exercises direct control over the bypass, but the national government exercises significant control over both. The bypassed institution may have conflicting views about the bypass, as it was created not as a parallel governance actor but as a supplement. Thus, conflicts could arise as national governments watch the bypass modify its mandate in order to remain relevant and effective.

\footnotetext{
${ }^{10}$ One of the main differences between this supplementary role and the role of an alternative (i.e., the bypass role) is the fact that the latter involves more conflict and competition, while the former involves more coordination and cooperation.
} 
In bypass situations, there is competition between parallel governance actors, but this is not necessarily always a hostile struggle for resources, especially if the bypass sees its primary role as improving the status of the bypassed institution - as is the case with WAHO. So, competition could involve a benign struggle for legitimacy amongst governance targets or amongst other governance actors, such as donor institutions, which might seek to support one governance actor over another based on perceptions of legitimacy or of effectiveness. For example, a West African citizen may prefer to use a WAHO facility because WAHO represents a broader sociocultural system that is not constrained by borders that divide communities, or simply because the services provided by institutions controlled by the national government are considered to be oppressive or noneffective.

These questions are part of a broader, somewhat unspoken debate about the role of WAHO and its mandate in a region with governance challenges. At the same time, they are also relevant conceptual questions for the concept of institutional bypass.

\section{Conclusion: WAHO's Unexplored Potential as an Institutional Bypass}

Officials of WAHO and the member state officials who work with them do not see WAHO as constituting a bypass. They continue to see WAHO as a supplement rather than an alternative. This makes WAHO not only an unintentional bypass, but one that performs both supplementary and bypassing roles, which are not mutually exclusive as cooperation and competition can coexist in complex institutional settings like West Africa.

It is not, at this point, fruitful to try to determine how successful WAHO has been in this role. Instead, the conversation should be focused on establishing how WAHO could and should better perform this function.

Functionally, WAHO is in a position to supply regional and national public goods and has done so, however minimally. While WAHO was not necessarily created to play this role, the peculiar character of the region (consisting primarily of states with governance challenges) has required the construction of alternative governance structures that remedy and replace fragile state institutions.

In addition to this functional role, it is important to look at WAHO's impact on the beneficiaries of governance functions (as measured by governance targets) and on other governance actors (particularly national health institutions). With regard to the former, WAHO provides direct services to citizens and institution in member states, as part of its mandate to improve health standards in the region. However, this affects its relationship with the latter, who are the primary providers of health services. How to make these interactions fruitful for both the beneficiaries and other governance actors is the question that we should turn to in the near future. 